\title{
Mechanical Properties of Bio-Based Epoxy Composites Reinforced with Hybrid-Interlayer Ramie and Recycled Carbon Fibres
}

\author{
Chenkai Zhu, Saihua Li, Xiaoye Cong, Xiaoling Liu* \\ University of Nottingham Ningbo China, Ningbo, China \\ Email: ^Xiaoling.Liu@nottingham.edu.cn
}

How to cite this paper: Zhu, C.K., Li, S.H., Cong, X.Y. and Liu, X.L. (2020) Mechanical Properties of Bio-Based Epoxy Composites Reinforced with Hybrid-Interlayer Ramie and Recycled Carbon Fibres. Open Journal of Composite Materials, 10, 118-133. https://doi.org/10.4236/ojcm.2020.104009

Received: July 20, 2020

Accepted: August 22, 2020

Published: August 25, 2020

Copyright ( 2020 by author(s) and Scientific Research Publishing Inc. This work is licensed under the Creative Commons Attribution International License (CC BY 4.0).

http://creativecommons.org/licenses/by/4.0/

\begin{abstract}
The growing environmental concerns have led to attention on bio-based composite materials, such as the natural fibres, recycled carbon fibres and bio-based resins. Herein, the bio-based epoxy composites were reinforced with ramie fibre $(\mathrm{RF})$ and recycled carbon fibre $(\mathrm{rCF})$ via inter-layer hybridisation. The dynamic mechanical analysis, tensile, flexural and impact properties characterisation were conducted to analyse the mechanical behaviour of the specimens. Also, the morphology of fractured surface after mechanical tests was studied under a scanning electron microscope. When the volume ratio between $\mathrm{RF}$ and $\mathrm{rCF}$ was varied from $100 / 0$ to $0 / 100$, the flexural and tensile strength of composites was significantly increased, while the impact strength was reduced. Thus the maximum values of flexural strength (182 $\mathrm{MPa}$ ) and tensile strength (165 MPa) were observed for rCF reinforced composite, whilst impact strength of $24 \mathrm{~kJ} / \mathrm{m}^{2}$ was found for RF reinforced composite. Furthermore, the values of storage and loss modulus were increased with the rCF incorporation due to a greater degree of restriction with the addition of rCF into the matrix. The hybridisation was able to combine the specific properties of RF and $\mathrm{rCF}$ and optimise the mechanical performance of composites. Therefore, the alternative low-cost green composites are prepared which can replace synthetic materials for semi-structural applications.
\end{abstract}

\section{Keywords}

Recycled Carbon Fibres, Ramie Fibres, Bio-Based Epoxy, Hybrid Interlayer, Mechanical Properties

\section{Introduction}

Composite materials are light-weight materials that are employed in transporta- 
tion (aviation, marine, and railway vehicles) and construction (such as bridges, wind turbine blade) industries due to their excellent mechanical performance, thermal insulation characteristics, fatigue, and corrosion resistance [1] [2]. For the composite matrix, the epoxy resin is widely used due to its good impregnation and adhesion to fibre reinforcement, resulting in excellent chemical and mechanical performance and low shrinkage after curing [3]. Also, the demand for carbon fibres (CF) has increased in the past decade, and with a compounded annual growth rate of $12 \%$, it is expected to escalate from 58,000 tonnes in 2015 to 116,000 tonnes in 2021 [4]. However, even though the use of these materials provides several advantages, they also present some challenges to the environment. The growth of volumes for carbon fibre reinforced composites today would inevitably lead to larger volumes of composite waste in near future [5].

A few studies have demonstrated that recycled carbon fibre ( $\mathrm{rCF}$ ) maintains high strength and modulus when compared with those of fresh carbon fibre [6] [7]. Furthermore, the cost of manufacturing $\mathrm{rCF}$ is approximately half of that for fresh CF. Therefore, application of $\mathrm{rCF}$ can decrease the price of carbon fibre reinforced composites. Hence, several processes are operating commercially for the recovery of carbon fibres from the end-of-life components, such as aircraft parts and tooling, in-process scrap such as out of shelf-life prepreg, and ply cutter offcuts [8].

Moreover, natural fibre reinforced composites are receiving increasing interest due to light-weight, low-cost, and excellent recyclability, and they provide a solution to the reuse of agricultural wastes [9]. Thus, in recent years, natural fibre (hemp, flax jute, and ramie) composites have been successfully used for light-weight and low-cost applications [10] [11] [12] [13]. Ramie fibre (RF), commonly known as China grass, is one of the oldest vegetable fibres and has been grown in China for several centuries. The fibres possess high strength, good durability, high absorbency with excellent lustre, and better chemical and bacterial resistance than other natural fibres [14]. When compared with synthetic fibres (glass fibre and carbon fibre), ramie fibre is a renewable green material with lower density and production cost [9]. However, significant barriers still exist for the structural applications of natural fibre reinforced composites. These barriers include the lack of confidence in the use and performance of natural plant fibres and their composites, their incompatibility with the hydrophobic polymer matrix, limited understanding of diffusion behaviour, lack of established manufacturing processes, and poor resistance to moisture [15].

Hybridisation refers to the combination of more than one type of fibre in the same matrix, can be an appropriate approach to take the advantages of both natural and synthetic fibres, as incorporation of fibres into a polymer can cause substantial changes in the mechanical properties of composites [15] [16]. This hybrid approach offers an attractive model for the fabrication of products with reduced cost and high specific modulus, strength, and elongation behaviour and impact resistance [17] [18]. 
Patel et al. [19] investigated the jute/carbon hybrid epoxy composites and found that the mechanical properties were improved with the alkali treatment and acrylation of jute fibres. Noorunnisa Khanam et al. [17] studied the mechanical properties of random sisal/carbon fibre reinforced hybrid composites with different fibre weight ratios and reported that both the tensile and flexural properties of the composites were increased with the carbon fibre loading. On the other hand, Le Guen et al. [20] and Ashworth et al. [21] worked on the damping coefficient of composites reinforced with hybrid flax/carbon and jute/carbon, respectively. The hybrid composites displayed better damping performance than the carbon fibre reinforced composites and higher mechanical performance than the natural fibre reinforced composites.

On the other hand, the researchers have focused on the replacement of petrochemical components in the resin matrix of composites with bio-based renewable equivalents. The renewable resources for resin matrix can provide a sustainable platform to partially or even completely substitute petroleum-based polymer resin via the design of bio-based polymer resin, which can compete with the existing petroleum-based polymers in terms of eco-friendliness values. Several bio-based epoxy resins derived from plant oils [22] [23] [24], lignin [25] [26], and rosin [27] [28] have been reported in literature. Some studies [29] [30] have also addressed the mechanical behaviour of composites made with rCF and epoxy composites.

However, there is no report in the literature on the hybrid, recycled carbon fibre/ramie fibre reinforced bio-based epoxy composites. Herein, the hybrid approach is hybrid-interlayer with a stacking sequence where stiff recycled carbon fibre mats are positioned at the outer-layers and more elastic ramie fabric at the inner-layers. The hybrid composites with "sandwich-structure" were fabricated to explore the effect of volume ratio of RF and $\mathrm{rCF}$ on the mechanical properties of the hybrid composites and develop light-weight, low-cost, and green composites with excellent mechanical performance. The nonwoven mat of rCF produced by the papermaking process and compression moulding for composite manufacture were studied. Dynamic mechanical analysis (DMA) was performed for hybrid composites, and tensile, flexural, impact tests were conducted. Scanning electron microscope (SEM) was used for the fracture morphological analysis of prepared specimens.

\section{Materials and Methods}

\subsection{Nonwoven Mat of Recycled Carbon Fibre}

A wet papermaking technique was employed to convert the recycled carbon fibres (ReCF ${ }^{\mathrm{TM}}-\mathrm{CP}$, average length: $3 \mathrm{~mm}$, Nantong Fuyuan Carbon Fibre Recycling, China) into a nonwoven mat with areal density of $100 \mathrm{~g} / \mathrm{m}^{2}$ (gsm). As shown in Figure 1, the process comprised of three steps. Around $10 \mathrm{~g}$ of recycled carbon fibres were weighed, added to a water solution of $10 \mathrm{~L}$, and stirred using a high shear radial impeller at a speed of $800 \mathrm{rpm}$ for $10 \mathrm{~min}$. The water 
solution contained $1 \mathrm{~g} / \mathrm{l}$ of PEO binding agent (Ryoji Organic Chemical, Japan) and $0.3 \mathrm{~g} / \mathrm{l}$ of anti-foaming agent (KR-XP96, Nanjing Kuorun Chemical, China). The process was undertaken using a tank with two impellers to ensure an efficient dispersion of the short fibres. Then, the fibre suspension was poured into another tank where the mesh was on the bottom. The mesh was slowly moved upwards to collect the dispersed recycled carbon fibres on the mesh to form a nonwoven mat. Finally, the collected mat was dried in an oven at $60^{\circ} \mathrm{C}$ for 12 hours.

\subsection{Composite Manufacture}

The composite specimens were manufactured via compression molding technique using a bio-based epoxy resin (AGMEP, ACC (Beijing) Science and Technology, China), and the detailed process is presented in Figure 2. The bio-based epoxy resin was pre-treated by mixing with acetone in 1:1 ratio to reduce the viscosity for easy mat ( $\mathrm{rCF}$ mat and $\mathrm{RF}$ fabric) impregnation. The impregnated mats were left in the fume hood for 8 hours for acetone evaporation. The areal weight of nonwoven $\mathrm{rCF}$ mat and plain weave ramie fabric (PR140, ACC (Beijing) Science and Technology, China) were $100 \mathrm{~g} / \mathrm{m}^{2}$ and $145 \mathrm{~g} / \mathrm{m}^{2}$, respectively.

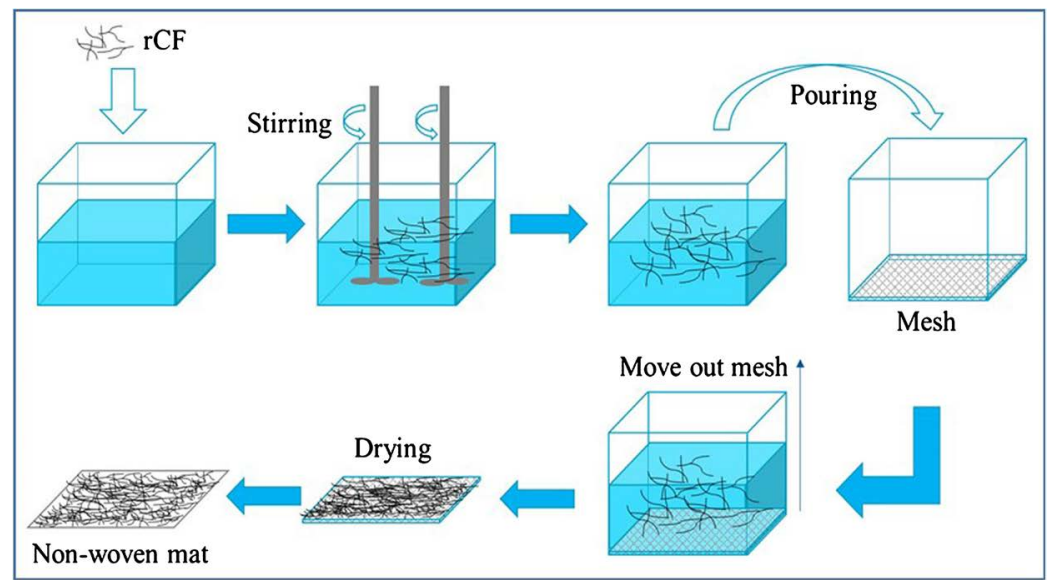

Figure 1. Schematic diagram of the recycled carbon fibre papermaking technique.

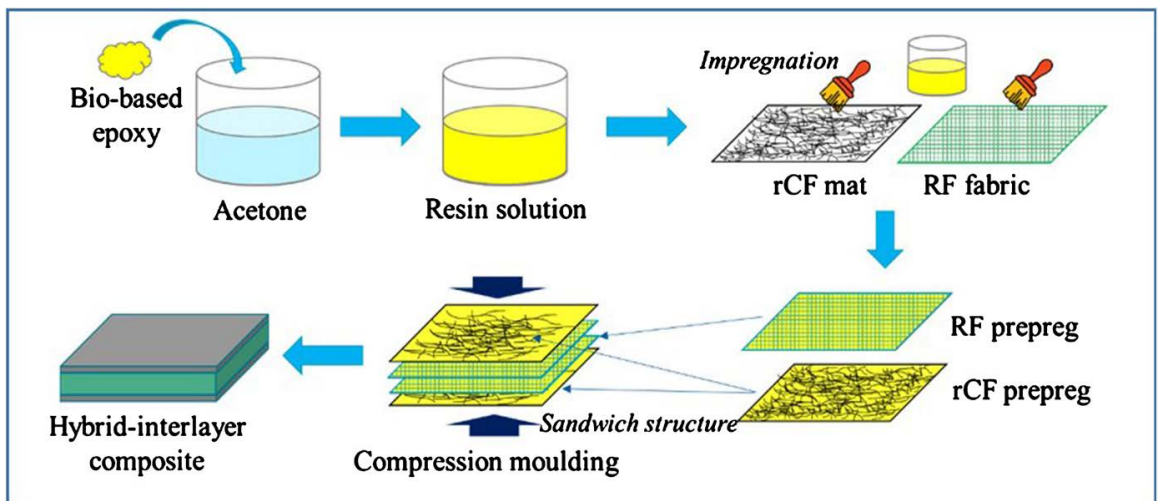

Figure 2. Schematic diagram of the composite manufacturing process. 
The final composites were manufactured via the layer stacking process (see Figure 2). The prepregs were stacked in a sandwich structure where the outer-layer was the rCF prepreg and inner-layer was RF prepreg. The stacked compound was placed in a $2 \mathrm{~mm}$ thick mold cavity between two metallic plates, pre-heated in the press at $90^{\circ} \mathrm{C}$ for $15 \mathrm{~min}$, and then, pressed at $10 \mathrm{bar}$ for $15 \mathrm{~min}$. This process was followed by curing at the same pressure and curing temperature of $130^{\circ} \mathrm{C}$ for $120 \mathrm{~min}$. The mould was then moved to the cooling plates of the press and held under the same pressure while cooling to room temperature.

In all composites, the overall fibre volume fraction was maintained at $30 \%$. The hybrid composites were named based on the ratio between RF and $\mathrm{rCF}$, as shown in Table 1.

\subsection{Mechanical Properties}

The tensile tests of composites were performed according to ISO 527-2 using a Universal Test Machine (E42, MTS, China) at the crosshead speed of $2 \mathrm{~mm} / \mathrm{min}$. The three-point bending test was conducted on Universal Test Machine (E42, MTS, China) as per ISO 14125 at the crosshead speed of $1 \mathrm{~mm} / \mathrm{min}$. The Izod impact test was performed using the impact machine (TE15, TQ, UK) in accordance with ISO 180 and unnotched specimens were prepared for testing. A minimum of five specimens were prepared for the tensile and flexural test, ten specimens for Izod impact test.

\subsection{Dynamic Mechanical Analysis}

Dynamic mechanical properties of the composites were assessed using a Dynamic Mechanical Analyser (DMA 8000, Perkin Elmer, USA) following ASTM D7028 standard. All the tests (specimen dimensions: $30 \times 10 \times 2 \mathrm{~mm}$ ) were performed in dual cantilever mode at $1 \mathrm{~Hz}$ frequency from $50^{\circ} \mathrm{C}$ to $250^{\circ} \mathrm{C}$ at a heating rate of $2^{\circ} \mathrm{C} / \mathrm{min}$.

\subsection{Microscope Observations}

The composite samples after flexural test were cooled in liquid nitrogen for 1 min and fractured manually. Care was taken to ensure that the fracture was created outside the zone of damage from flexural testing. Also, putter coating with gold was performed on the samples after tensile tests and the cross-section of the

Table 1. Bio-based epoxy composites used in the study.

\begin{tabular}{cccc}
\hline Sample code & $\begin{array}{c}\text { Layer number ratio } \\
(\mathrm{RF} / \mathrm{rCF})\end{array}$ & $\begin{array}{c}\text { Volume fraction ratio } \\
(\mathrm{RF} / \mathrm{rCF})\end{array}$ & Stacking sequence \\
\hline $8 \mathrm{RF}$ & $8 / 0$ & $100 / 0$ & $\mathrm{RF}_{8}$ \\
6RF2rCF & $6 / 2$ & $75 / 25$ & $\mathrm{rCF}_{1} / \mathrm{RF}_{6} / \mathrm{rCF}_{1}$ \\
$4 \mathrm{RF} 2 \mathrm{rCF}$ & $4 / 4$ & $50 / 50$ & $\mathrm{rCF}_{2} / \mathrm{RF}_{4} / \mathrm{rCF}_{2}$ \\
$2 \mathrm{RF} 6 \mathrm{rCF}$ & $2 / 6$ & $25 / 75$ & $\mathrm{rCF}_{3} / \mathrm{RF}_{2} / \mathrm{rCF}_{3}$ \\
$8 \mathrm{rCF}$ & $0 / 8$ & $0 / 100$ & $\mathrm{rCF}_{8}$ \\
\hline
\end{tabular}


composite samples was examined under scanning electron microscope (SEM, Sigma VP; Zeiss, Oberkochen, Germany) operated at $10 \mathrm{kV}$.

\subsection{Statistical Analysis}

The average values and standard error of all the data presented were calculated and analysed using the Prism software (version 6.0, GraphPad Software, San Diego, CA, USA). A one-way analysis of variance (ANOVA) was calculated with Tukey multiple post-test to compare the significance of the change in one factor with time. The error bars on all the data represent standard error of the mean.

\section{Results and Discussion}

\subsection{Dynamic Mechanical Analysis}

As shown in Figure 3, the storage modulus of composites decreased with temperature, being higher for the composite with more recycled carbon fibres ( $\mathrm{rCF}$ ). Even a small content of rCF displayed a pronounced effect on the storage modulus of the hybrid interlayer composite in the glassy and elastomeric regions. The modulus of composites in the glassy state is primarily determined via the strength of intermolecular forces and the packing of polymer chains [31]. An improvement in the modulus can be a result of the incorporation of reinforcement which led to composite stiffness. Besides, an increase in modulus by $\mathrm{rCF}$ incorporation should be because of both higher modulus of $\mathrm{rCF}$ than ramie fibre and stronger adhesion to the polymer chains at the interface [32].

On the other hand, with an increase in temperature, there was a decrease in the storage modulus (Figure 3), displaying a sharp fall when passing through the glass transition region. This drop was affected by the reinforcing effect of the $\mathrm{rCF} / \mathrm{ramie}$ fibre in the epoxy matrix. The decrease of modulus with an increase in temperature is based on the Micro-Brownian motion of the polymer chains as the polymer approached the glass transition temperature, $\mathrm{T}_{\mathrm{g}}$. The $\mathrm{Mi}$ cro-Brownian movement is related to the cooperative short-range diffusional motion of the main chain segments and to their relaxation stress [32] [33]. The

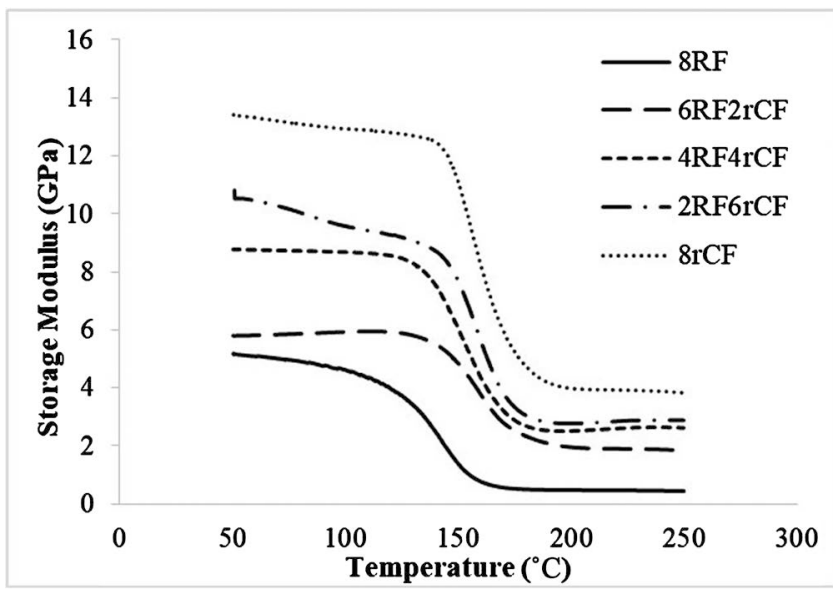

Figure 3. Storage modulus of hybrid inter-layer bio-based epoxy composite. 
decrease in modulus of composites with increase in temperature can also be attributed to the effect of fibre stiffness and fibre matrix adhesion.

Figure 4 presents the loss modulus as a function of temperature for different relative ratio (RF:rCF). In DMA analysis, the loss modulus is the contribution of the viscous component and is indicative of the energy dissipated by the system [34]. The loss modulus reached the peak values and decreased with the increase in temperature. This behaviour is caused by the free movement of polymer chains at higher temperatures. The rapid rise in loss modulus indicates an increase in the polymer structural mobility due to a relaxation process that allows much more motion along the chain than that is possible when the temperature is below $\mathrm{T}_{\mathrm{g}}[35]$.

When rCF was incorporated in the composites, higher loss modulus peak values were obtained. These results can possibly be attributed to the inhibition of the relaxation process in the composites with the increased amount of chain segments and free volume owing to fibre addition [36]. Moreover, an increase in the modulus peak values with rCF addition may be indicative of a structure with higher internal friction that improves the energy dissipation, implying changes in molecular dynamics in this region [36] [37].

The peak value of tan delta is associated with the partial motion of a polymer structure; thus, indicative of the glass transition temperature $T_{g}$ where a material changes from the rigid to elastic state [38]. The tan delta as a function of temperature for different relative volume ratio (RF:rCF) is shown in Figure 5 and the glass transition temperature, $\mathrm{T}_{\mathrm{g}}$, corresponding to peak value of tan delta are listed in Table 2. $\mathrm{T}_{\mathrm{g}}$ was found to increase when the recycled carbon fibre replaced the ramie fibre. This temperature shift with the increase in the recycled carbon fibre content is related to the higher energy required to reach maximum dissipation [39].

\subsection{Flexural Properties}

The properties of composites and corresponding failure mode hybrid composites are primarily dependent on the fibre (recycled carbon and ramie fibre) content and layer stacking sequence. According to the literature [34], due to the

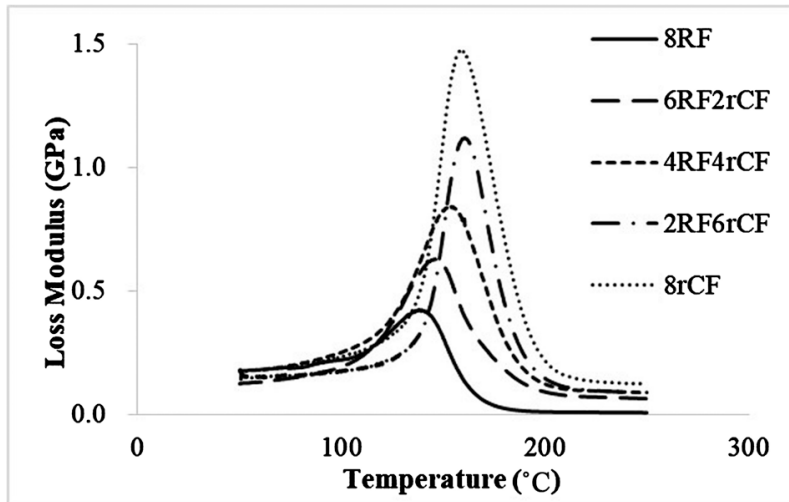

Figure 4. Loss modulus of hybrid interlayer bio-based epoxy composite. 


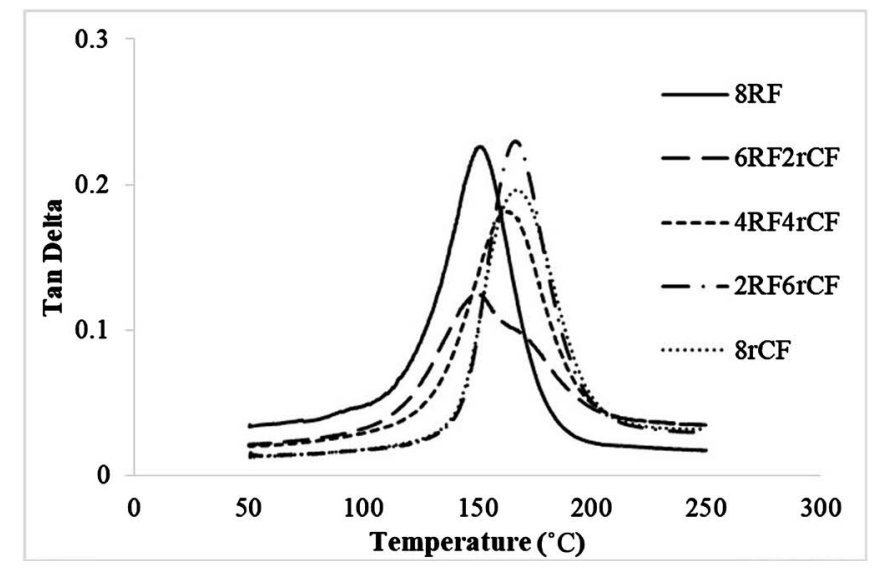

Figure 5. Tan delta of hybrid interlayer bio-based epoxy composite.

Table 2. Peak value of loss modulus and glass transition temperature of hybrid composites.

\begin{tabular}{cccc}
\hline Sample code & Loss modulus peak $(\mathrm{GPa})$ & Tan delta peak & $\mathrm{T}_{\mathrm{g}}\left({ }^{\circ} \mathrm{C}\right)$ \\
\hline 8RF & 0.42 & 0.23 & 151 \\
$6 \mathrm{RF} 2 \mathrm{rCF}$ & 0.63 & 0.13 & 149 \\
$4 \mathrm{RF} 4 \mathrm{rCF}$ & 0.84 & 0.18 & 164 \\
$2 \mathrm{RF} 6 \mathrm{rCF}$ & 1.12 & 0.23 & 167 \\
$8 \mathrm{rCF}$ & 1.47 & 0.20 & 167 \\
\hline
\end{tabular}

difference in surface morphology and functional groups between carbon fibre and ramie fibre, the fibre-matrix adhesion at the carbon fibre-epoxy and ramie fibre-epoxy interface was different. On the other hand, the tensile modulus could be improved by $23 \%$ and strength by $10 \%$ depending on the stacking sequence, where the carbon fibres at the outer-layer led to higher tensile properties [40]. Therefore, the hybrid interlayer composites were designed as a sandwich structure with recycled carbon fibre in the outer-layer (see Figure 2).

The load-displacement curves obtained from the flexural testing are displayed in Figure 6, and the flexural strength and modulus of composites are presented in Figure 7. Based on the comparison of load-displacement behaviour of composites, composites with pure rCF reinforced exhibited linear curves with a sudden drip of the load after the peak load. However, with the hybridisation of RF with layered structure, the load-displacement curve changed from linear to more prolonged nonlinear. With the substitution of RF by $\mathrm{rCF}$, the peak load for composite failure was increased, and the $\mathrm{rCF}$ reinforced composite (8rCF) displayed the highest peak value of $200 \mathrm{~N}$. Meanwhile, the elongation of composites decreased as the addition of $\mathrm{rCF}$ could change the composites' specific properties from "ductile" to "brittle".

As shown in Figure 7, the rCF reinforced composite $(8 \mathrm{rCF})$ displayed the highest flexural strength of $182 \mathrm{MPa}$ and modulus of $19 \mathrm{GPa}$. In contrast, the flexural strength and modulus for $8 \mathrm{RF}$ composite without rCF were $75 \mathrm{MPa}$ and $6 \mathrm{GPa}$, respectively. When $\mathrm{RF}$ was replaced with $\mathrm{rCF}$ in hybridisation, an 


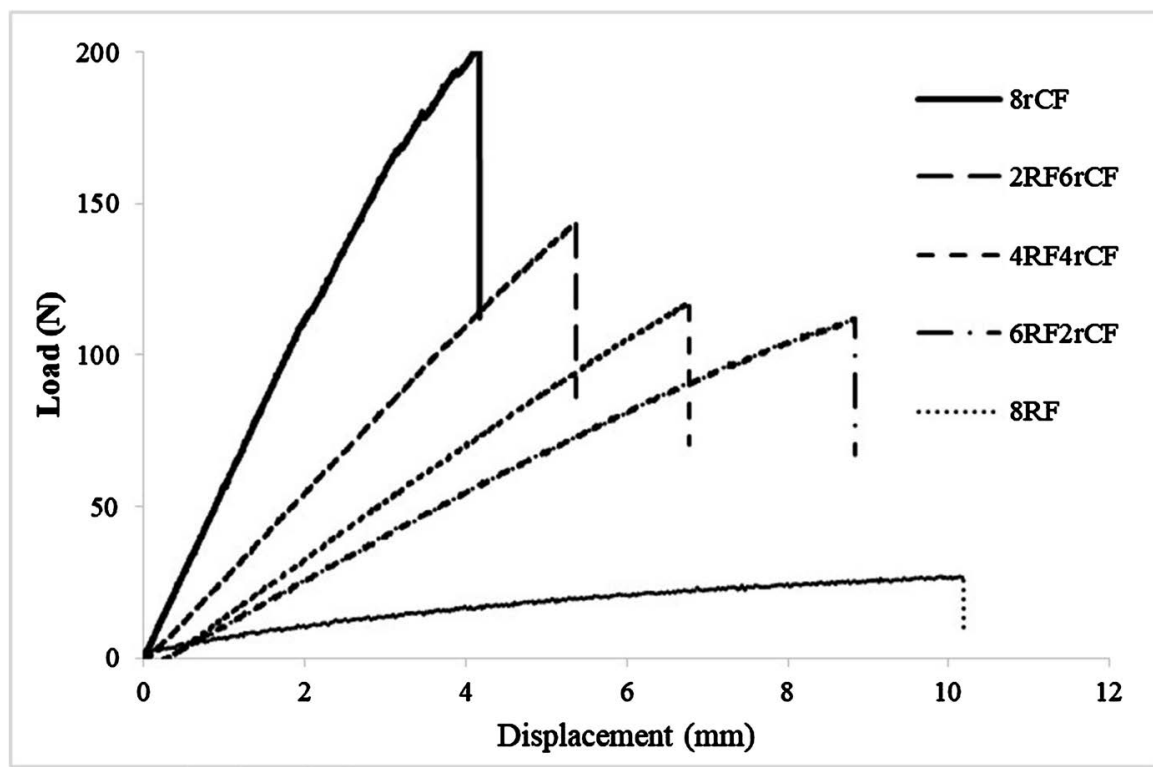

Figure 6. Load displacement curves of flexural testing for hybrid interlayer bio-based epoxy composite.

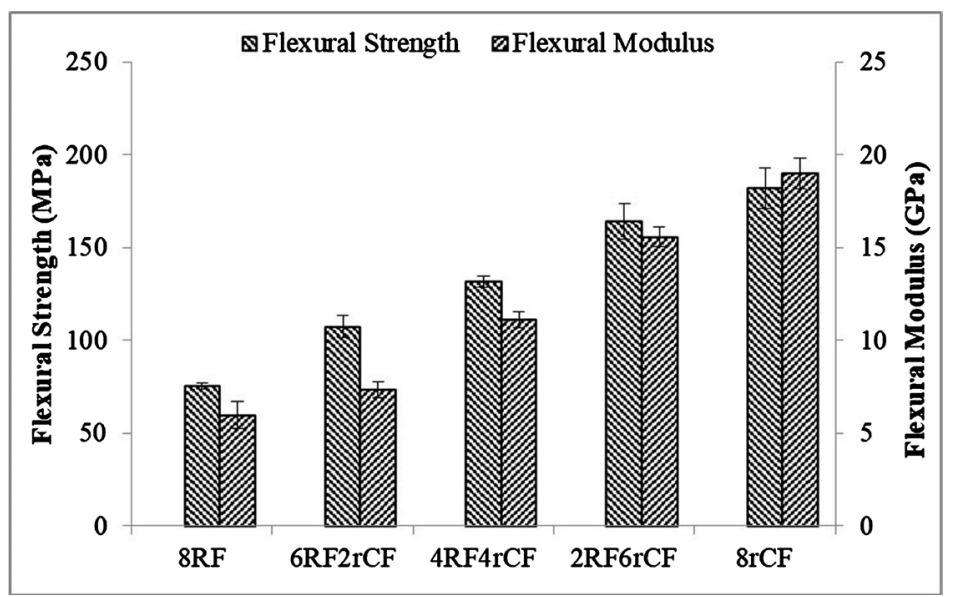

Figure 7. Flexural properties of hybrid interlayer bio-based epoxy composite.

increase in flexural strength was observed from $107 \mathrm{MPa}$ (6RF2rCF composite) to $131 \mathrm{MPa}$ (4RF/4rCF composite) and $164 \mathrm{MPa}$ (2RF6rCF composite). Also, the flexural modulus was increased from $7 \mathrm{GPa}$ (6RF2rCF composite) to $11 \mathrm{GPa}$ (4RF/4rCF composite) and $16 \mathrm{GPa}$ (2RF6rCF composite).

Herein, the hybrid composites were designed as a sandwich structure where $\mathrm{rCF}$ is in outer-layer and RF in the inner-layer. The flexural strength and modulus were significantly affected by the properties of reinforcement closest to the outer-layer surface of the specimens, of which the top surface experienced the compression force, and the bottom surface tension force [15]. Hence, the total bending deflection behaviour is a combination of the compression and tension deflection. The rCF with better mechanical properties in the outer-layer surface of the composite could provide higher performance in tension and compression during the bending. 


\subsection{Tensile Properties}

The tensile force-extension curves obtained for the composite reinforced by $\mathrm{rCF}$, $\mathrm{RF}$, and hybrid reinforcement are shown in Figure 8, while Figure 9 presents the tensile properties. Similar to the flexural properties behaviour, the tensile strength and modulus increased upon the replacement of ramie fibres with recycled carbon fibres. The hybrid composite with the highest tensile strength (165 $\mathrm{MPa}$ ) and modulus (17 GPa) was reinforced purely with rCF (8rCF composite). The 8 RF composite with fully RF reinforced exhibited the lowest tensile strength of $44 \mathrm{GPa}$ and modulus of $5 \mathrm{GPa}$. This difference is due to the stronger and stiffer characteristics of $\mathrm{rCF}$ in comparison with the RF, even though the reinforcement as nonwoven mat for $\mathrm{rCF}$ and plain weave for $\mathrm{RF}$.

Figure 10 shows an SEM image of the fractured surface in the tensile test for different hybridisation structures. The failure mechanism for $8 \mathrm{rCF}$ composites fully reinforced with rCF was matrix cracking, fibre fracture, and pull-out. For the $8 \mathrm{RF}$ composite with RF reinforcement, there was an indication of matrix cracking and fibre pull-out with fibre extension. However, for carbon fibre hybridised composites, there was a considerable amount of matrix cracking and

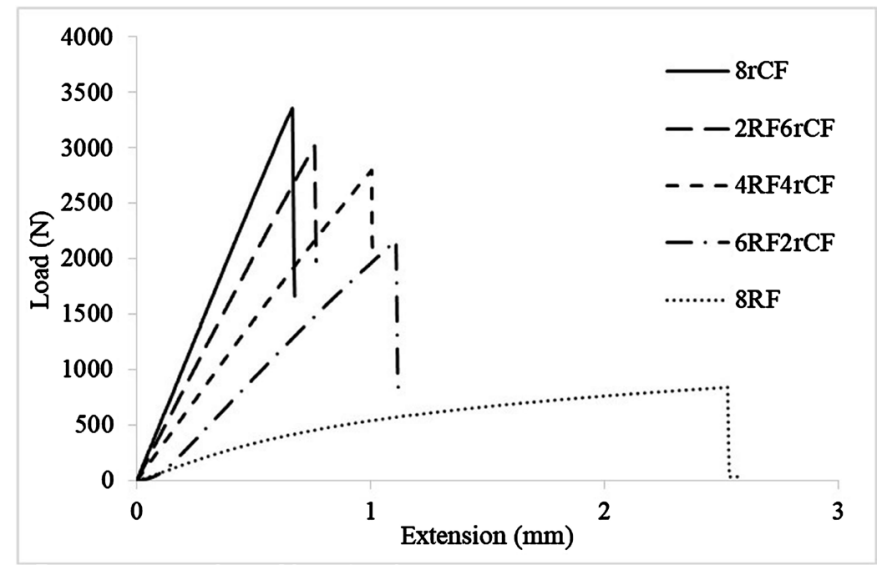

Figure 8. Load extension curves of tensile testing for hybrid interlayer bio-based epoxy composite.

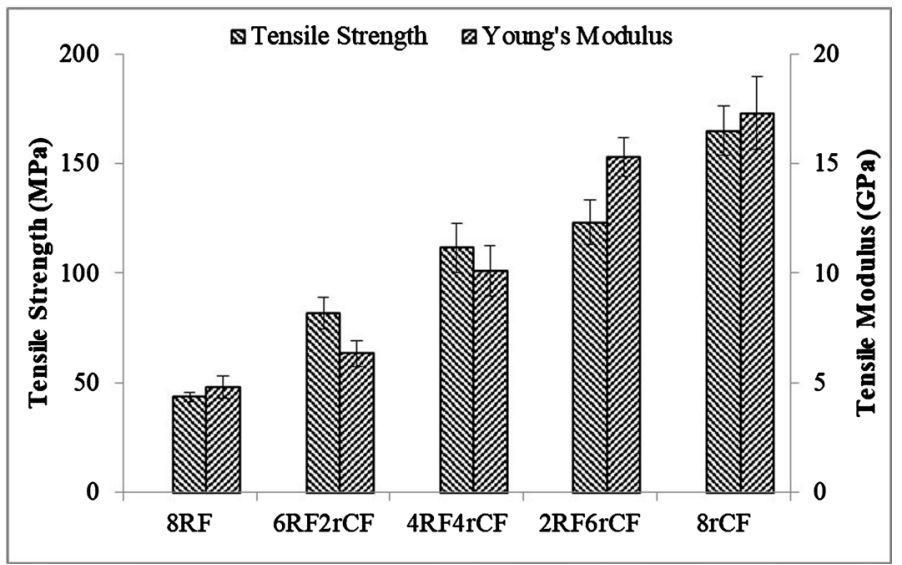

Figure 9. Tensile properties of hybrid interlayer bio-based epoxy composite. 


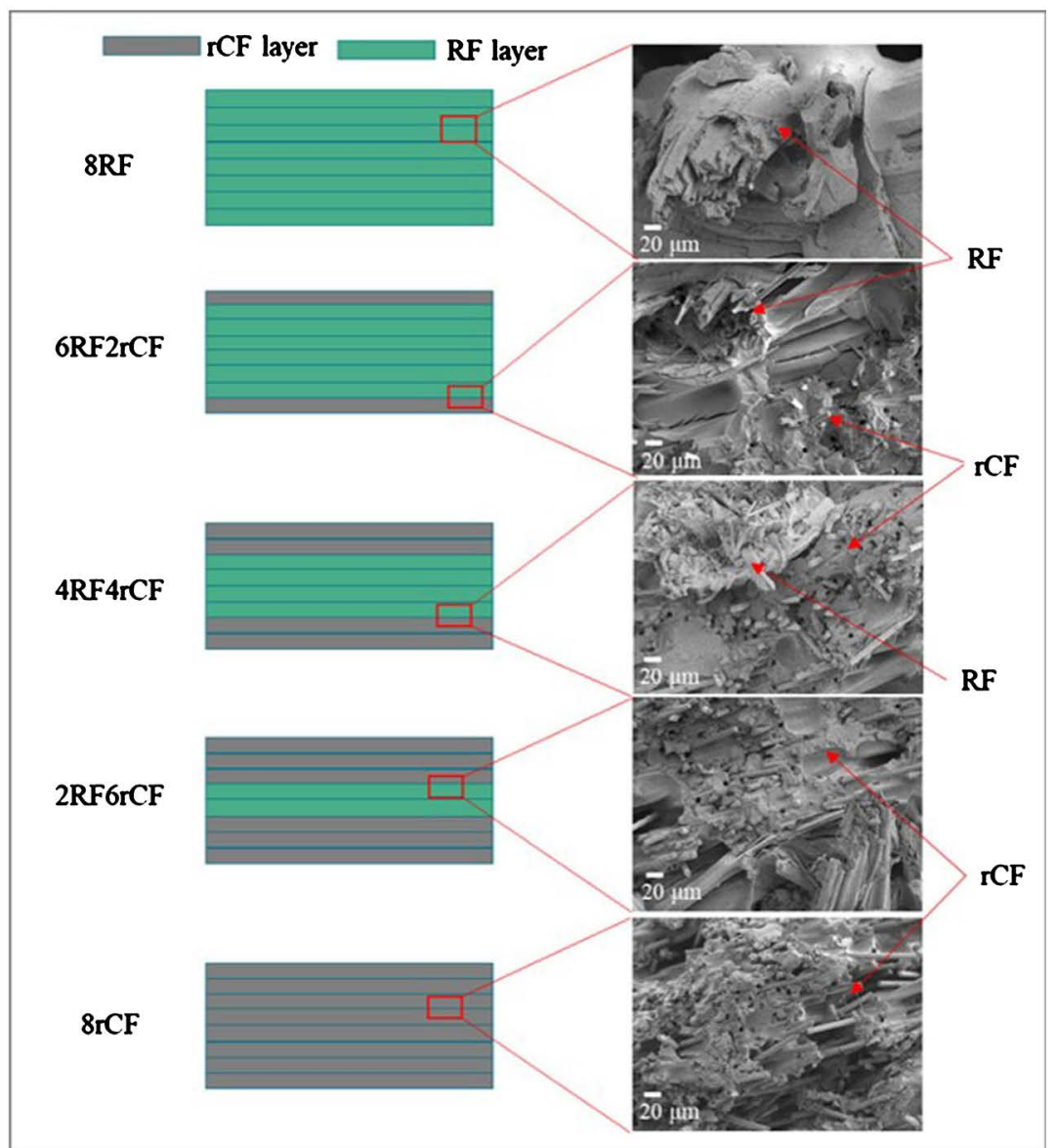

Figure 10. Structural design and SEM images of fractured surface for hybrid interlayer bio-based epoxy composite after tensile testing.

pull-out of RF and rCF. In general, the fibre pull-out occurs when the interfacial stress at the fibre matrix interface exceeds the interfacial strength, causing the fibre to debond from the matrix. Therefore, fibre treatment or resin modification should be considered to improve the interface for rCF-matrix and RF-matrix.

\subsection{Impact Properties}

Figure 11 shows the impact strength results of the composites. When rCF was replaced by RF in the composites, the impact strength was significantly increased and the maximum value of $24 \mathrm{~kJ} / \mathrm{m}^{2}$ was observed for $8 \mathrm{RF}$ composite. As expected, RF reinforced composite showed a better energy absorption capability when compared with other hybrid composites and rCF reinforced composite.

Several studies in literature have reported the improvement on the impact resistance of carbon fibre reinforced composite via hybridisation with natural fibre. Ramana and Ramprasad [41] reported the $46 \%$ improvement of impact strength registered for hybrid composites when jute fibres replaced 50\% carbon fibres. Sarasini et al. [42] also confirmed the impact absorption energy of hybrid composite could be improved with the addition of natural fibre laminate. They also compared different stacking sequences of hybrid composite, found that 


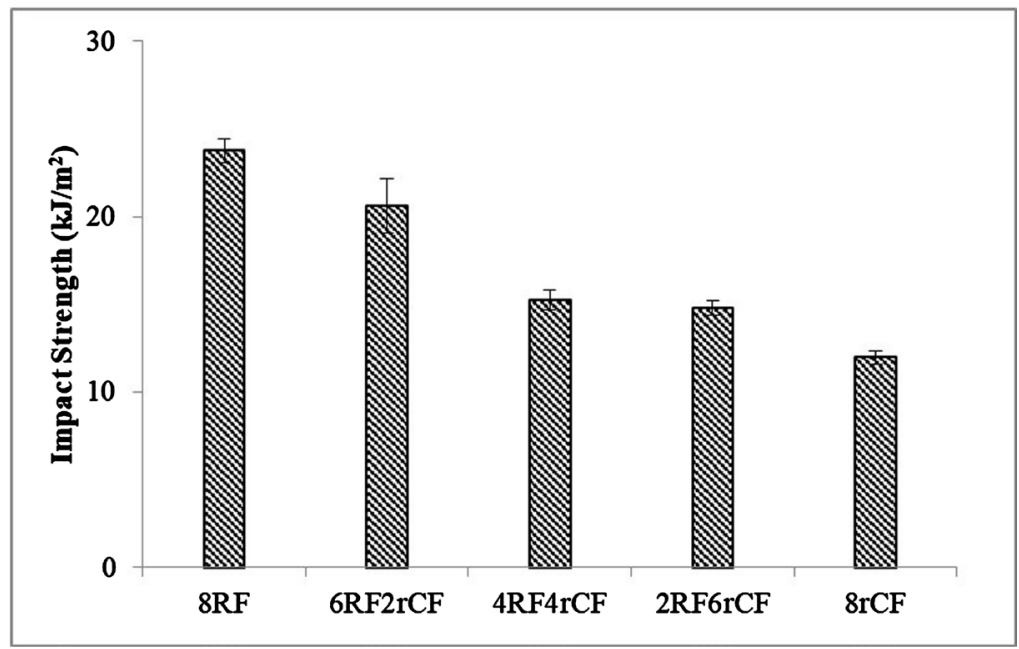

Figure 11. Impact strength of hybrid interlayer bio-based epoxy composite.

hybrid flax-carbon-flax stacking structure presented better impact absorption performance as flax fibre in the out-layer could dissipate higher amount of impact energy. As such, the mechanical performance of hybrid interlayer composites with RF-rCF-RF structure where ramie fibre in the outer-layer could be considered in future study, to figure out the effect of stacking sequence on the hybrid composite performance.

As a result, the hybridisation allows the modification of material characteristics and combination of the good properties of $\mathrm{rCF}$ (i.e. high stiffness) and $\mathrm{RF}$ (i.e. good toughness and elongation behaviour). The volume ratio and fibre distribution of hybrid composites can be designed to follow the requirements of the application. As such, the hybrid composites in this study presented better flexural and tensile performance than 8RF composite and higher impact strength than $8 \mathrm{rCF}$ composite. Additionally, such hybrid composites would be entirely "green". Except for RF and bio-based epoxy matrix, the rCF can be considered as a low-cost renewable material because of direct recycling from the carbon fibre reinforced composites instead of manufacturing from raw material.

On the other hand, the nonwoven mat technique for rCF has the freedom for fibre orientation. The random mats of $\mathrm{rCF}$ herein displayed isotropic behaviour, whilst a strong fibre orientation such as UD mat can be obtained to enhance the composite performance in specific direction. Hence, they may obtain multifunctional characteristics to compete with completely synthetic composites. The hybrid $\mathrm{RF} / \mathrm{rCF}$ composites can be considered as a possible alternative to the current traditional composites, such as glass fibre reinforced composites, for semi-structural applications. However, the compressive and fatigue resistance need to be investigated in future studies for further understanding of the hybridisation of natural fibres and recycled carbon fibres.

\section{Conclusions}

The growing environmental concerns have led to increased attention towards 
the use of bio-based composite materials, such as the natural fibres and bio-based resins. Also, an increase in the waste carbon fibre reinforced composites (CFRP) has resulted in issues about the utilisation of recycled carbon fibre $(\mathrm{rCF})$. As ramie fibre (RF) reinforced composites have been limited to non-load bearing applications due to low mechanical properties, a possible solution can be the hybridisation to combine natural fibre and recycled carbon fibres.

In this study, the fully green hybrid $\mathrm{RF} / \mathrm{rCF}$ reinforced bio-based epoxy composites were developed. When the hybrid ratio of $\mathrm{rCF}$ was increased from $0 \%$ to $100 \%$, the flexural and tensile strength of the composites was increased by $141 \%$ and $275 \%$, respectively; while a decrease by $50 \%$ was observed for impact strength due to RF with better toughness was replaced by rCF. Furthermore, the storage and loss modulus were found to increase with the rCF incorporation. These results can be attributed to the high stiffness of $\mathrm{rCF}$, which resulted in the inhibition of the relaxation process in composites with the increased amount of chain segments and free volume.

The current work elucidates on the preliminary insights into novel green composites via hybridisation, to combine the advantage of rCF with high stiffness and RF with good toughness. The as-prepared hybrid composites with relatively improved mechanical performance can be considered as an alternative low-cost green material to replace the traditional composites for semi-structural applications. For future study, the interface performance study on composite could be taken into account.

\section{Acknowledgements}

The authors acknowledge the financial support from Ningbo S \& T bureau under Commonweal Research Programme (Project code: 2019C50027), Ningbo S\&T Bureau Collaboration Project (Project code: 2017D10030), Ningbo High-Tech Zone "New Carbon Fibre Composite Technologies and Materials in Aerospace Functional Application", and Zhejiang Innovation Team "Multi-functional green composite for the next generation aerospace application".

\section{Conflicts of Interest}

The authors declare no conflicts of interest regarding the publication of this paper.

\section{References}

[1] Li, J.J., Zhu, C.K., Zhao, Z.J., Khalili, P., Clement, M., Tong, J.F., Liu, X.L. and Yi, X.S. (2019) Fire Properties of Carbon Fiber Reinforced Polymer Improved by Coating Nonwoven Flame Retardant Mat for Aerospace Application. Journal of Applied Polymer Science, 136, 47801-47814. https://doi.org/10.1002/app.47801

[2] Zhu, C.K., Li, J.J., Ji, F.H., Yi, X.S., Rudd, C. and Liu, X.L. (2019) Sandwich Structure Composite with Expandable Graphite Filled or Coated: Evaluation of Flame Retardancy and Mechanical Performances. Open Journal of Safety Science and Technology, 9, 7-21. https://doi.org/10.4236/ojsst.2019.91002 
[3] Zhu, C.K., Li, J.J., Clement, M., Yi, X.S., Rudd, C. and Liu, X.L. (2019) The Effect of Intumescent Mat on Post-Fire Performance of Carbon Fibre Reinforced Composites. Journal of Fire Sciences, 37, 257-272. https://doi.org/10.1177/0734904119849395

[4] Witik, R.A., Teuscher, R., Michaud, V., Ludwig, C. and Månson, J.A.E. (2013) Carbon Fibre Reinforced Composite Waste: An Environmental Assessment of Recycling, Energy Recovery and Landfilling. Composites Part A: Applied Science and Manufacturing, 49, 89-99. https://doi.org/10.1016/j.compositesa.2013.02.009

[5] Wong, K., Rudd, C., Pickering, S. and Liu, X.L. (2017) Composites Recycling Solutions for the Aviation Industry. Science China Technological Sciences, 60, 1291-1300. https://doi.org/10.1007/s11431-016-9028-7

[6] Pimenta, S. and Pinho, S.T. (2012) The Effect of Recycling on the Mechanical Response of Carbon Fibres and Their Composites. Composite Structures, 94, 3669-3684. https://doi.org/10.1016/j.compstruct.2012.05.024

[7] Turner, T.A., Pickering, S.J. and Warrior, N.A. (2011) Development of Recycled Carbon Fibre Moulding Compounds-Preparation of Waste Composites. Composites Part B: Engineering, 42, 517-525. https://doi.org/10.1016/j.compositesb.2010.11.010

[8] Pickering, S.J., Liu, Z., Turner, T.A. and Wong, K.H. (2016) Applications for Carbon Fibre Recovered from Composites. IOP Conference Series: Materials Science and Engineering, 139, Article ID: 012005. https://doi.org/10.1088/1757-899X/139/1/012005

[9] Dong, C. (2018) Review of Natural Fibre-Reinforced Hybrid Composites. Journal of Reinforced Plastics and Composites, 37, 331-348. https://doi.org/10.1177/0731684417745368

[10] Boccarusso, L., Carrino, L., Durante, M., Formisano, A., Langella, A. and Minutolo, F.M.C. (2016) Hemp Fabric/Epoxy Composites Manufactured by Infusion Process: Improvement of Fire Properties Promoted by Ammonium Polyphosphate. Composites Part B: Engineering, 89, 117-126. https://doi.org/10.1016/j.compositesb.2015.10.045

[11] Dey, K., Sharmin, N., Khan, R.A., Nahar, S., Parsons, A.J. and Rudd, C.D. (2011) Effect of Iron Phosphate Glass on the Physico-Mechanical Properties of Jute Fabric-Reinforced Polypropylene-Based Composites. Journal of Thermoplastic Composite Materials, 24, 695-711. https://doi.org/10.1177/0892705711401848

[12] Kandare, E., Luangtriratana, P. and Kandola, B.K. (2014) Fire Reaction Properties of Flax/Epoxy Laminates and Their Balsa-Core Sandwich Composites with or without Fire Protection. Composites Part B: Engineering, 56, 602-610. https://doi.org/10.1016/j.compositesb.2013.08.090

[13] Choi, H.Y. and Lee, J.S. (2012) Effects of Surface Treatment of Ramie Fibers in a Ramie/Poly(Lactic Acid) Composite. Fibers and Polymers, 13, 217-223. https://doi.org/10.1007/s12221-012-0217-6

[14] Sen, T. and Reddy, H.J. (2011) Various Industrial Applications of Hemp, Kinaf, Flax and Ramie Natural Fibres. International Journal of Innovation, Management and Technology, 2, 192-198.

[15] Dhakal, H., Zhang, Z., Guthrie, R., Macmullen, J. and Bennett, N. (2013) Development of Flax/Carbon Fibre Hybrid Composites for Enhanced Properties. Carbohydrate Polymers, 96, 1-8. https://doi.org/10.1016/j.carbpol.2013.03.074

[16] Reis, P.N.B., Ferreira, J.A.M., Antunes, F.V. and Costa, J.D.M. (2007) Flexural Behaviour of Hybrid Laminated Composites. Composites Part A: Applied Science and 
Manufacturing, 38, 1612-1620. https://doi.org/10.1016/j.compositesa.2006.11.010

[17] Khanam, P.N., Khalil, H.A., Jawaid, M., Reddy, G.R., Narayana, C.S. and Naidu, S.V. (2010) Sisal/Carbon Fibre Reinforced Hybrid Composites: Tensile, Flexural and Chemical Resistance Properties. Journal of Polymers and the Environment, 18, 727-733. https://doi.org/10.1007/s10924-010-0210-3

[18] Kureemun, U., Ravandi, M., Tran, L.Q.N., Teo, W.S., Tay, T.E. and Lee, H.P. (2018) Effects of Hybridization and Hybrid Fibre Dispersion on the Mechanical Properties of Woven Flax-Carbon Epoxy at Low Carbon Fibre Volume Fractions. Composites Part B: Engineering, 134, 28-38. https://doi.org/10.1016/j.compositesb.2017.09.035

[19] Patel, V.A., Bhuva, B.D. and Parsania, P.H. (2009) Performance Evaluation of Treated-Untreated Jute-Carbon and Glass-Carbon Hybrid Composites of Bisphenol-C Based Mixed Epoxy-Phenolic Resins. Journal of Reinforced Plastics and Composites, 28, 2549-2556. https://doi.org/10.1177/0731684408093973

[20] Le Guen, M.J., Newman, R.H., Fernyhough, A., Emm, G.W. and Staiger, M.P. (2016) The Damping-Modulus Relationship in Flax-Carbon Fibre Hybrid Composites. Composites Part B: Engineering, 89, 27-33.

https://doi.org/10.1016/j.compositesb.2015.10.046

[21] Ashworth, S., Rongong, J., Wilson, P. and Meredith, J. (2016) Mechanical and Damping Properties of Resin Transfer Moulded Jute-Carbon Hybrid Composites. Composites Part B: Engineering, 105, 60-66. https://doi.org/10.1016/j.compositesb.2016.08.019

[22] Gupta, A., Ahmad, S. and Dev, A. (2011) Modification of Novel Bio-Based Resin-Epoxidized Soybean Oil by Conventional Epoxy Resin. Polymer Engineering \& Science, 51, 1087-1091. https://doi.org/10.1002/pen.21791

[23] Stemmelen, M., Pessel, F., Lapinte, V., Caillol, S., Habas, J.P. and Robin, J.J. (2011) A Fully Biobased Epoxy Resin from Vegetable Oils: From the Synthesis of the Precursors by Thiol-Ene Reaction to the Study of the Final Material. Journal of Polymer Science Part A: Polymer Chemistry, 49, 2434-2444. https://doi.org/10.1002/pola.24674

[24] Fombuena, V. (2013) Study of the Properties of Thermoset Materials Derived from Epoxidized Soybean Oil and Protein Fillers. Journal of the American Oil Chemists Society, 90, 449-457. https://doi.org/10.1007/s11746-012-2171-2

[25] Hofmann, K. and Glasser, W.G. (1993) Engineering Plastics from Lignin. 22. Cure of Lignin Based Epoxy Resins. The Journal of Adhesion, 40, 229-241. https://doi.org/10.1080/00218469308031286

[26] El Mansouri, N.-E., Yuan, Q. and Huang, F. (2011) Synthesis and Characterization of Kraft Lignin-Based Epoxy Resins. Bioresources, 6, 2492-2503.

[27] Deng, L.L., Shen, M.M., Yu, J., Wu, K. and Ha, C.Y. (2012) Preparation, Characterization, and Flame Retardancy of Novel Rosin-Based Siloxane Epoxy Resins. Industrial \& Engineering Chemistry Research, 51, 8178-8184. https://doi.org/10.1021/ie201364q

[28] Liu, X., Huang, W., Jiang, Y., Zhu, J. and Zhang, C. (2012) Preparation of a Bio-Based Epoxy with Comparable Properties to Those of Petroleum-Based Counterparts. eXPRESS Polymer Letters, 6, 293-298. https://doi.org/10.3144/expresspolymlett.2012.32

[29] Pimenta, S., Pinho, S.T., Robinson, P., Wong, K.H. and Pickering, S.J. (2010) Mechanical Analysis and Toughening Mechanisms of a Multiphase Recycled CFRP. Composites Science and Technology, 70, 1713-1725. https://doi.org/10.1016/j.compscitech.2010.06.017 
[30] Oliveux, G., Dandy, L.O. and Leeke, G.A. (2015) Current Status of Recycling of Fibre Reinforced Polymers: Review of Technologies, Reuse and Resulting Properties. Progress in Materials Science, 72, 61-99. https://doi.org/10.1016/j.pmatsci.2015.01.004

[31] Cowie, J.M.G. and Arrighi, V. (2007) Polymers: Chemistry and Physics of Modern Materials. 3rd Edition, CRC Press, Boca Raton. https://doi.org/10.1201/9781420009873

[32] Ornaghi Jr., H.L., Da Silva, H.S.P., Zattera, A.J. and Amico, S.C. (2011) Hybridization Effect on the Mechanical and Dynamic Mechanical Properties of Curaua Composites. Materials Science and Engineering: A, 528, 7285-7289. https://doi.org/10.1016/j.msea.2011.05.078

[33] Romanzini, D., Ornaghi Junior, H.L., Amico, S.C. and Zattera, A.J. (2012) Preparation and Characterization of Ramie-Glass Fiber Reinforced Polymer Matrix Hybrid Composites. Materials Research, 15, 415-420. https://doi.org/10.1590/S1516-14392012005000050

[34] Shamsuyeva, M., Hansen, O. and Endres, H.-J. (2019) Review on Hybrid Carbon/Flax Composites and Their Properties. International Journal of Polymer Science, 2019, Article ID: 9624670. https://doi.org/10.1155/2019/9624670

[35] Pothan, L.A., George, C.N., John, M.J. and Thomas, S. (2010) Dynamic Mechanical and Dielectric Behavior of Banana-Glass Hybrid Fiber Reinforced Polyester Composites. Journal of Reinforced Plastics and Composites, 29, 1131-1145. https://doi.org/10.1177/0731684409103075

[36] Hameed, N., Sreekumar, P., Francis, B., Yang, W. and Thomas, S. (2007) Morphology, Dynamic Mechanical and Thermal Studies on Poly (Styrene-Co-Acrylonitrile) Modified Epoxy Resin/Glass Fibre Composites. Composites Part A: Applied Science and Manufacturing, 38, 2422-2432.

https://doi.org/10.1016/j.compositesa.2007.08.009

[37] Ratna, D. and Banthia, A.K. (2000) Toughened Epoxy Adhesive Modified with Acrylate Based Liquid Rubber. Polymer International, 49, 281-287. https://doi.org/10.1002/(SICI)1097-0126(200003)49:3\%3C281::AID-PI353\%3E3.0.C $\mathrm{O} ; 2-\mathrm{F}$

[38] Pothan, L.A., Oommen, Z. and Thomas, S. (2003) Dynamic Mechanical Analysis of Banana Fiber Reinforced Polyester Composites. Composites Science and Technology, 63, 283-293. https://doi.org/10.1016/S0266-3538(02)00254-3

[39] Ornaghi Jr., H.L., Bolner, A.S., Fiorio, R., Zattera, A.J. and Amico, S.C. (2010) Mechanical and Dynamic Mechanical Analysis of Hybrid Composites Molded by Resin Transfer Molding. Journal of Applied Polymer Science, 118, 887-896.

[40] Fehri, M., Ragueh, R.R., Vivet, A., Dammak, F. and Haddar, M. (2017) Improvement of Natural Fiber Composite Materials by Carbon Fibers. Journal of Renewable Materials, 5, 38-47. https://doi.org/10.7569/JRM.2016.634123

[41] Ramana, M.V. and Ramprasad, S. (2017) Experimental Investigation on Jute/Carbon Fibre Reinforced Epoxy Based Hybrid Composites. Materials Today: Proceedings, 4, 8654-8664. https://doi.org/10.1016/j.matpr.2017.07.214

[42] Sarasini, F., Tirillò, J., D’Altilia, S., Valente, T., Santulli, C., Touchard, F., Chocinski-Arnault, L., Mellier, D., Lampani, L. and Gaudenzi, P. (2016) Damage Tolerance of Carbon/Flax Hybrid Composites Subjected to Low Velocity Impact. Composites Part B: Engineering, 91, 144-153. https://doi.org/10.1016/j.compositesb.2016.01.050 